\title{
Cancer of unknown primary: a population-based analysis of temporal change and socioeconomic disparities
}

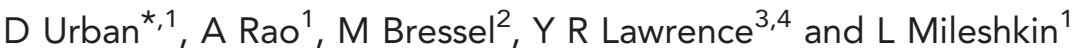

${ }^{1}$ Division of Cancer Medicine, Peter MacCallum Cancer Centre, Locked Bag No. 1, A'Beckett Street, East Melbourne, Victoria 3002 Australia; ${ }^{2}$ Centre for Biostatistics and Clinical Trials, Peter MacCallum Cancer Centre, Locked Bag No. 1, A'Beckett Street, East Melbourne, Victoria 3002, Australia; ${ }^{3}$ Department of Oncology, Sheba Medical Center, Ramat Gan 52621, Israel and ${ }^{4}$ Department of Radiation Oncology, Thomas Jefferson University, Kimmel Cancer Center, 111 South 11th Street, Philadelphia, PA 19107, USA

Background: Cancer of unknown primary (CUP) is the fourth most common cause of cancer death. With advanced diagnostics and treatments, we investigated the proportion of cancers diagnosed as CUP, treatment outcomes and association with socioeconomic disparities.

Methods: We analysed trends in CUP diagnosis and outcome within the Surveillance, Epidemiology, and End Results registry between 1973 and 2008.

Results: The percentage of all cancers diagnosed as CUP has decreased over time comprising $<2 \%$ of cancers since 2007 . A higher proportion of CUP was diagnosed in the elderly, females, blacks and residents of less affluent or less educated counties. Median survival of all CUP patients was 3 months, with no improvement over time. The 5-year survival significantly improved in those with squamous histology (squamous cell carcinoma; SCC) but only marginally in non-SCC. Factors associated with a longer survival on multivariate analysis included white race; female; $<65$ years old; most recent decade at diagnosis; SCC; married; a histological diagnosis; and treatment with radiotherapy (all $P<0.001$ ). Despite the improvement in survival with radiotherapy, its use was less frequent in females and blacks.

Conclusion: The percentage of cancers diagnosed as CUP is decreasing but prognosis remains poor, particularly in non-SCC CUP. However, significant socioeconomic disparities exist in diagnosis and survival, suggesting inequalities in access to diagnostic investigations and treatment.

Cancer of unknown primary (CUP) is the seventh or eighth most frequent malignancy in various parts of the developed world. Historically, it has accounted for 3-5\% of all malignancies, and was the fourth most common cause of cancer-related death (Pavlidis and Pentheroudakis, 2010, 2012).

A diagnosis of CUP should be limited to patients with histological confirmation of metastatic cancer, in whom a standard diagnostic approach does not reveal a primary tumour (Pavlidis and Pentheroudakis, 2012). The CUP is recognised as being a heterogeneous entity with a wide variety of presentations, and is usually characterised by aggressive or unpredictable behaviour and a poor prognosis (Morris et al, 2010). In addition, a diagnosis of CUP may be associated with significant psychological distress for the patient (Abbruzzese et al, 1995; Boyland and Davis, 2008).

Given the poor prognosis, uncertain treatment and psychological stress associated with a diagnosis of CUP, much research has been invested into diagnostic strategies, such as gene expression profiling (Bridgewater et al, 2008), to determine the 
primary site and guide management. However, in spite of these improvements in diagnostic investigations and possibly even management of CUP, there is little literature describing the changing patterns of CUP diagnosis and prognosis over time in the United States (Muir, 2006) and even less data describing socioeconomic disparities in this cohort (Muir, 1995; Fong et al, 2008). This study aimed to describe the recent trends in CUP diagnoses in a large US cohort, with a particular focus on socioeconomic disparities and factors correlated with survival.

\section{MATERIALS AND METHODS}

Data sources. Patients with cancer and those with CUP were identified from the Surveillance, Epidemiology, and End Results (SEER) program of the National Cancer Institute. The SEER program is a comprehensive source of population-based data in the United States, based on tumour registries that cover an $\sim 26 \%$ of the US population and $>2800000$ patients. Individual patient data was collected from the SEER 17 registries between 1973 and 2008. The SEER 9, 13 and 17 registries were used to retrieve the age-standardised (to the 2000 US standard population) incidence of CUP in the years 1973-1991, 1992-1999 and 2000-2008, respectively.

Study population and inclusion criteria. Patients with CUP were defined as those patients for whom the primary site was classified as 'unknown primary site' (ICD-O-3 code 80.9 ) and active followup data (excluding autopsy-only cases) was available. To minimise possible confounding from synchronous or metachronous cancer diagnoses, patients with multiple primaries were excluded. Patients with haematological malignancies (ICD-03 codes 9590/3-9989/3) were excluded. As only 94 patients (and 2 being squamous cell carcinoma (SCC)) were recorded in SEER as having isolated, anatomically specified lymph node involvement (ICD-O-3 codes C77.0-77.5) with the above inclusion/exclusion criteria, these were not included in our analysis. With respect to analysis of carcinoma by subtype, the following ICD-03 codes were used: adenocarcinoma (8140-8389); SCC (8050-8089); carcinoma not otherwise specified (NOS; 8010-8049) and neuroendocrine (8240/3, 8241/3, $8243 / 3,8244 / 3,8245 / 3,8246 / 3$ and $8249 / 3$ ). Patients who did not have a histological confirmation were included in the survival analysis. The majority of these patients (95\%) had a histological classification of NOS.

Study variables. Available data in the SEER files included year of diagnosis, histology, tumour grade, use of radiotherapy as part of first treatment and demographic factors (sex, age at diagnosis, race, marital status, poverty and educational status). The proportion of patients with CUP was defined as the number of patients with CUP divided by the number of patients with all types of nonhaematological cancers.

Education status was defined by the percentage of people having at least a bachelor's degree registered as a county attribute in the SEER. This data was extracted for all non-haematological cancer cases with active follow-up in the years 1990-99 and 2000-2008, and was divided into quartiles. Poverty was categorised into three groups based on the median regional income: affluent $(<10 \%)$, middle (10-19.9\%) and poor ( $\geqslant 20 \%$; Singh et al, 2003).

The survival duration after cancer diagnosis was measured in months and was restricted to patients with carcinomas (adenocarcinoma, SCC, neuroendocrine and carcinoma NOS). To ensure that those who did not survive a full month after diagnosis (and thus represent those with the poorest prognosis) were included in the analysis; patients coded in the SEER data set as having a survival time of zero were assigned a survival time of one half-month according to standard methods (Koepsell and Weiss, 2003). The multivariate analysis was limited to CUP patients diagnosed after 1990, as education and poverty status are not recorded in SEER for the period 1973-1989. The numbers lost to follow-up was $<5 \%$, as SEER registries must meet or exceed a $95 \%$ follow-up rate.

Statistical analyses. Statistical analyses were performed using SEER ${ }^{\star}$ Stat 7.0.5 (Surveillance Research Program, National Cancer Institute, Bethesda, MD, USA) and STATA 12.1 (STATA Corp, College Station, TX, USA). Overall survival was described using the Kaplan-Meier method from the date of diagnosis to the date of death from any cause. The effects of demographical, pathological and treatment variables on multivariate analyses were tested using the Cox proportional hazards model. Patients who had missing data were excluded from the multivariate analysis. A two sided $P$-value $<0.05$ was considered statistically significant.

\section{RESULTS}

\section{Trends in incidence and proportion of patients with CUP}

Demographics. The demographic details, treatment and outcome data for the 106641 CUP patients identified in the SEER database are outlined in Table 1.

Diagnosis of CUP. Both the incidence and proportion of CUP have decreased over time, with the former only beginning to decline after 1980 (Figure 1). Over the study period, the proportion of CUP decreased to a greater extent than the incidence of CUP. From 1973 to 2008, the proportion of CUP decreased by $51 \%$ and the incidence decreased by $30 \%$. Since 2007 , the proportion of cancers diagnosed as CUP has fallen below $2 \%$.

Despite recommendations that CUP can only be classified after histological confirmation, a pathological diagnosis of carcinoma was confirmed in only $78 \%$ of patients $(n=80,822)$. This did not change considerably from the 1970 s to the 2000 s, (76.5\% vs $77.1 \%$, respectively). For those who survived $<1$ month, only $56.9 \%$ of patients were histologically confirmed. In comparison, $88.2 \%$ of patients who survived for at least 3 months did have a pathological diagnosis.

Socioeconomic disparities in the diagnosis of CUP. The proportion of cancer cases diagnosed as CUP decreased over time within all subgroups analysed. However, disparities between different socioeconomic groups are evident.

Gender. Females represent the majority of CUP patients (52.2\%), except in the squamous cell histology group (32.6\%). The proportion of cancers diagnosed as CUP according to gender has changed over time (Figure 2). In the early years of analysis, the proportion was slightly greater in males, but since 1987, the proportion has been consistently greater in females. Females were also less likely to have pathological confirmation of their disease (75.6\% vs $80.1 \%$ in males, $P<0.001$ ).

Race. The proportion of CUP was higher in blacks than in whites throughout the study period (Figure 2). However, there was no significant difference between the proportion of CUP in blacks living in affluent areas and the general white population (2066 vs 2172 vs 1952 cases per 100000 cancers in affluent blacks $v s$ all whites $v s$ affluent whites, respectively). There were no major differences in the rate of pathological confirmation by race $(77.4 \%, 79.0 \%$ and $79.7 \%$ in whites, blacks and others, respectively).

Socioeconomic factors. Since the mid-1990s, the proportion of CUP cases was lower in areas of higher education and affluence, compared with less educated and poorer areas (Figure 2). 
Table 1. Demographic characteristics, treatment and outcome data for CUP patients

\begin{tabular}{|c|c|c|c|c|c|}
\hline & $\begin{array}{c}\text { All }^{\mathrm{a}}(\%) \\
n=106641\end{array}$ & $\begin{array}{c}\text { Adeno CA } \\
n=38511(36.1 \%)\end{array}$ & $\begin{array}{c}\text { Squamous } \\
n=9058(8.5 \%)\end{array}$ & $\begin{array}{c}\text { NOS } \\
n=32357(30.3 \%)\end{array}$ & $\begin{array}{c}\text { Neuroendocrine } \\
n=3390(3.2 \%)\end{array}$ \\
\hline \multicolumn{6}{|l|}{ Gender (males) } \\
\hline & 50994 (47.8\%) & $17033(44.2)$ & $6102(67.4)$ & $15690(48.5)$ & $1655(48.8)$ \\
\hline \multicolumn{6}{|c|}{ Median age (range) } \\
\hline & $72(0-113)$ & $70(0-106)$ & $65(2-103)$ & $74(0-113)$ & $66(13-85)$ \\
\hline \multicolumn{6}{|l|}{ Grade $^{b}$} \\
\hline $\begin{array}{l}1 \\
2 \\
3 \\
4\end{array}$ & $\begin{array}{c}954(4.9 \%) \\
3074(15.8 \%) \\
10911(56.1 \%) \\
4517(23.2 \%)\end{array}$ & $\begin{array}{c}497(6.1 \%) \\
1946(24.1 \%) \\
5244(64.8 \%) \\
402(5.0 \%)\end{array}$ & $\begin{array}{c}180(7.8 \%) \\
670(29.2 \%) \\
1347(58.7 \%) \\
99(4.3 \%)\end{array}$ & $\begin{array}{c}17(0.3) \\
52(0.8) \\
3112(47.3 \%) \\
3397(51.6 \%)\end{array}$ & $\begin{array}{r}91(20.1 \%) \\
65(14.4 \%) \\
196(43.4 \%) \\
100(22.1 \%)\end{array}$ \\
\hline \multicolumn{6}{|l|}{ Race } \\
\hline $\begin{array}{l}\text { White } \\
\text { Black } \\
\text { Other }\end{array}$ & $\begin{array}{c}88814(83.7 \%) \\
11098(10.5 \%) \\
6227(5.9 \%)\end{array}$ & $\begin{array}{c}31638 \text { (82.5\%) } \\
4189 \text { (10.9\%) } \\
2524 \text { (6.6\%) }\end{array}$ & $\begin{array}{c}7683(85.7 \%) \\
885 \text { (9.9\%) } \\
395(4.4 \%)\end{array}$ & $\begin{array}{c}27263 \text { (84.6\%) } \\
3174 \text { (9.9\%) } \\
1798 \text { (5.6\%) }\end{array}$ & $\begin{array}{c}2843(84.1 \%) \\
393(11.6 \%) \\
143(4.2 \%)\end{array}$ \\
\hline \multicolumn{6}{|l|}{ Radiotherapy } \\
\hline $\begin{array}{l}\text { None } \\
\text { Radiotherapy } \\
\text { Refused }\end{array}$ & $\begin{array}{c}83555 \text { (79.7\%) } \\
20182(19.2 \%) \\
1168 \text { (1.1\%) }\end{array}$ & $\begin{array}{c}30770(81.0 \%) \\
6917(18.2 \%) \\
295(0.8 \%)\end{array}$ & $\begin{array}{c}4044(45.8 \%) \\
4682(53.0 \%) \\
101(1.1 \%)\end{array}$ & $\begin{array}{c}26109 \text { (81.8\%) } \\
5421 \text { (17.0\%) } \\
381 \text { (1.2\%) }\end{array}$ & $\begin{array}{c}2871(86.2 \%) \\
438(13.2 \%) \\
20(0.6 \%)\end{array}$ \\
\hline \multicolumn{6}{|l|}{ Marital } \\
\hline $\begin{array}{l}\text { Married } \\
\text { Single } \\
\text { Previously married }\end{array}$ & $\begin{array}{l}49780(49.0 \%) \\
13186(13.0 \%) \\
38645(38.0 \%)\end{array}$ & $\begin{array}{r}19307(52.4 \%) \\
4519(12.3 \%) \\
13026(35.4 \%)\end{array}$ & $\begin{array}{l}4653(54.6 \%) \\
1278(15.0 \%) \\
2599(30.5 \%)\end{array}$ & $\begin{array}{r}14490(46.9 \%) \\
3823(12.4 \%) \\
12567(40.7 \%)\end{array}$ & $\begin{array}{r}1857(57.3 \%) \\
437(13.5 \%) \\
947(29.2 \%)\end{array}$ \\
\hline \multicolumn{6}{|c|}{ Median survival months (range) } \\
\hline & $2(0-430)^{c}$ & $2(0-394)$ & $15(0-400)$ & $2(0-426)$ & $11(0-334)$ \\
\hline \multicolumn{6}{|c|}{$\begin{array}{l}\text { Abbreviations: } C A=\text { carcinoma; } C U P=\text { carcinoma of unknown primary; NOS = not otherwise specified. } \\
\text { a Other histologies included unspecified }(15 \%) \text {, sarcoma }(<1 \%) \text { and others }(1 \%) \text {. } \\
\text { b }_{\text {Data on grade were available for } 19456 \text { patients. }} \\
{ }^{C} \text { This is the only survival analysis that included all CUP patients. All other survival analyses were limited to patients with carcinoma. }\end{array}$} \\
\hline
\end{tabular}

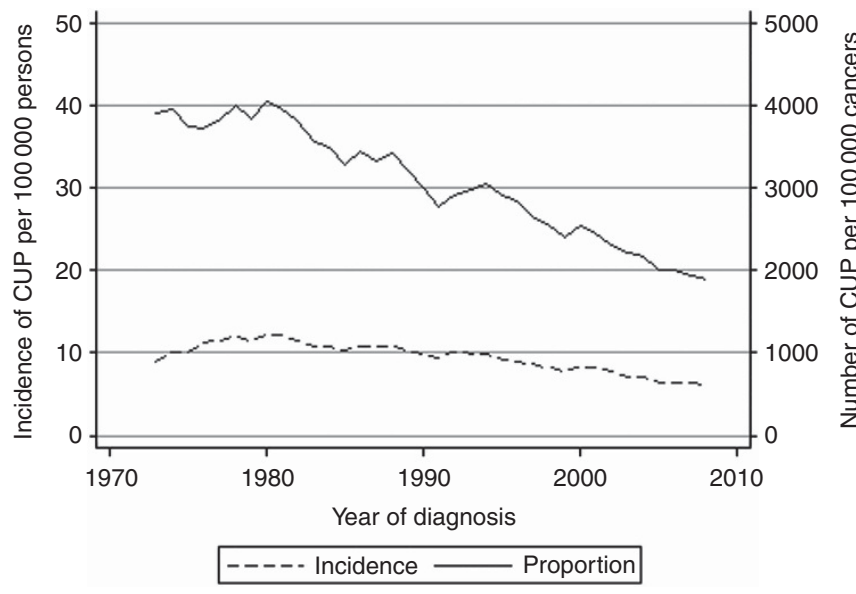

Figure 1. The trends in incidence of CUP diagnosed per 100000 persons and the proportion of all cancers diagnosed as CUP, between the years 1973 and 2008.

A pathological confirmation was also more common in the more affluent $(78.6 \%$ vs $74.3 \%$ in poor, $P<0.001)$ and better educated (79.2\% vs $73.7 \%$ in least educated, $P<0.001)$ areas.
Age. The proportion of CUP was consistently higher in patients 65 years and older compared with those younger than 65 . However, both age groups recorded a decrease in the proportion of cancers diagnosed as CUP over time (Figure 3). Since 1994, the proportion of cancers diagnosed as CUP fell below $2 \%$ in patients under 65 years old, whereas the proportion of CUP continue to remain above $2.5 \%$ among those older than 65 . When adjusting for age, disparities in the proportion of CUP diagnoses by level of education and affluence remained (data not shown). The elderly were also less likely to have pathological confirmation $(71.3 \%$ vs $90.8 \%, P<0.001)$.

Survival of patients with CUP. The median survival of all CUP carcinoma patients was 3 months (range $0-430$ months), with no improvement in the median survival over time in the overall cohort. The 12-month survival rate of CUP patients was 53\% and $48 \%$ for SCCs and neuroendocrine carcinomas, respectively, but only $15 \%$ for both adenocarcinomas and carcinomas NOS. There was only a minor increase in 5 year survival in non-squamous carcinoma over time $(3.9 \%$ vs $5.8 \%$ for those diagnosed in 1973-1979 and 2000-20008, respectively). However, there was a significant improvement in the 5-year survival in SCC $(15.0 \%$ vs $41.1 \%$ for those diagnosed in 1973-1979 and 2000-2008, respectively Figure 4). Evidence of an improvement in the median 

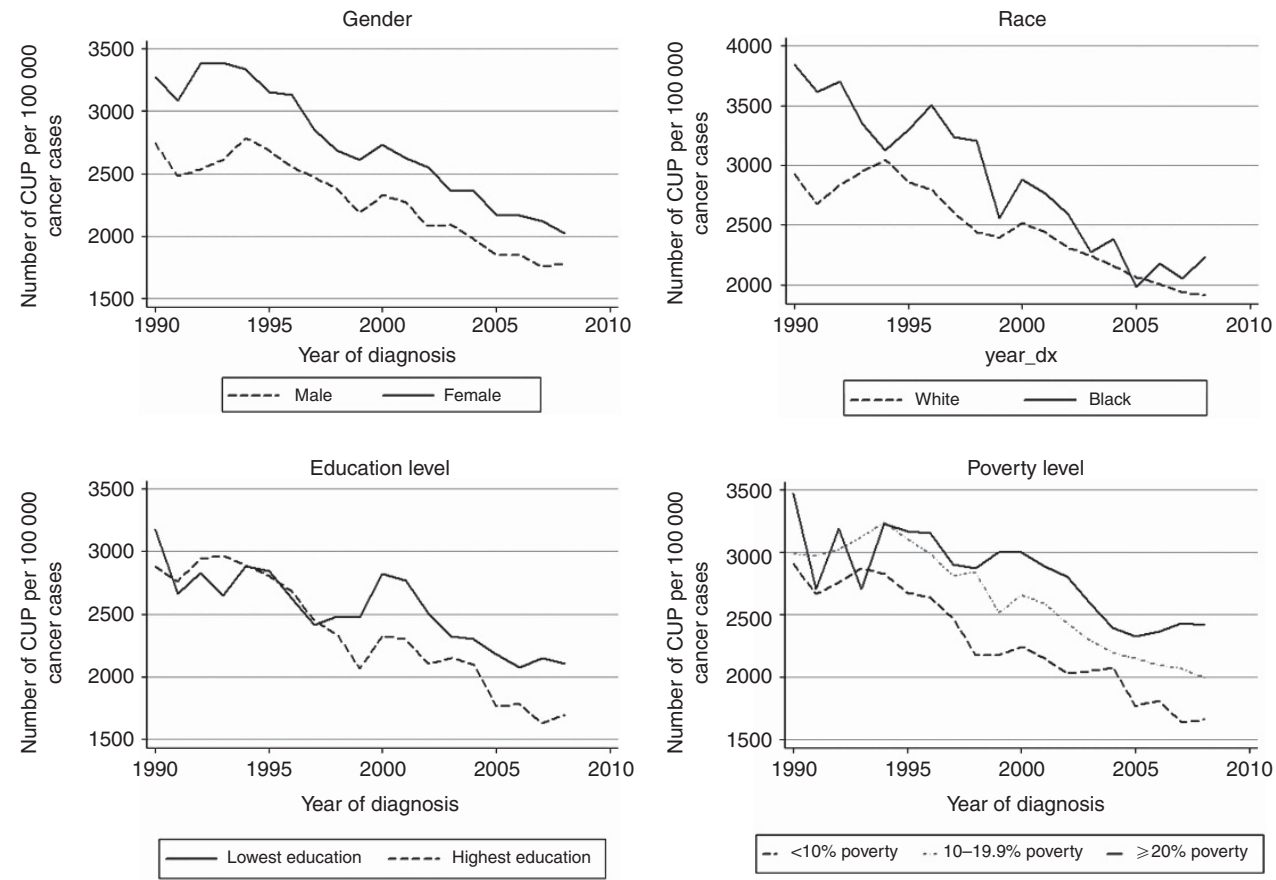

Figure 2. Proportion of CUP diagnoses per 100000 cancers by socioeconomic factors (gender, race, education and poverty level). Proportion was calculated as a percentage of all cancers diagnosed as CUP within each subgroup per year. Education status was defined by the percentage of people having at least a bachelor's degree registered as a county attribute in SEER. The lowest and highest education quartiles are graphed. Poverty was categorised into three groups based on the median regional income: affluent $(<10 \%)$, middle $(10-19.9 \%)$ and poor $(\geqslant 20 \%)$.

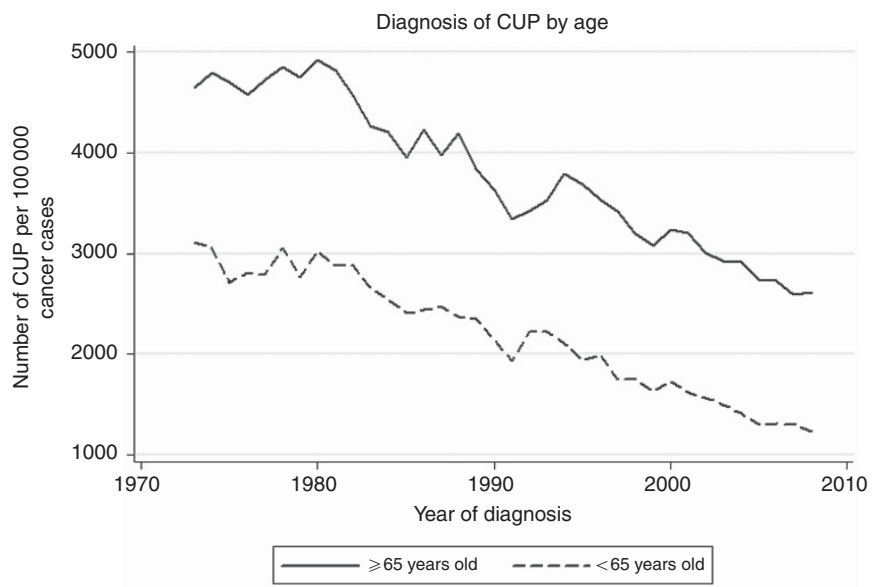

Figure 3. Proportion of CUP diagnoses per 100000 cancers by age. The proportion was calculated as a percentage of all cancers diagnosed as CUP per age group.

survival was limited to SCCs in whom a significant increase from 7 to 25 months was recorded, from the years 1973-1979 to 2000-2008. In contrast, the median survival of adenocarcinomas decreased from 3 to 2 months and for neuroendocrine carcinomas from 18 to 10 months, in the years 1973-1979 and 2000-2008, respectively. There was no change in the median survival of 2 months for CUP NOS. The median survival of patients with a pathological confirmation was 3 months compared with 1 month without pathological confirmation, with no significant differences according to decade of diagnosis. As $95 \%$ of those without a histological diagnosis were classified as CUP NOS, we analysed the median survival for CUP NOS separately for those with and without histological confirmation. The median survival of CUP NOS with a histological confirmation was 3 months in 1973-1979 and 2 months in 2000-2008, whereas the median survival of CUP NOS without a histological confirmation was 1 month in both the time periods. Approximately $16 \%$ of patients died within 1 month of diagnosis, more commonly among patients without a histological confirmation $(34.7 \%$ vs $13.1 \%)$.

Variables associated with an improved overall survival on multivariate analysis included white race (compared with black); female gender; age <65 years at diagnosis; SCC (compared with non-squamous); a histological diagnosis; currently married (compared with single or previously married); higher education; and radiotherapy, (all $P<0.001$, Table 2). Given grade was only available for 11929 patients diagnosed since 1990; it was excluded from the multivariate analysis.

The overall survival of black patients diagnosed with CUP was shorter $(\mathrm{HR}=1.11, \mathrm{CI}=1.08-1.14, P<0.001)$. In particular, the median survival of SCC patients improved significantly more in whites compared with blacks. From 1973-1979 to 2000-2008, the median survival of white patients with SCC improved from 7-32 months, compared with a change from $4-8$ months in blacks.

Use of RT in CUP. The use of radiotherapy decreased over time with $22 \%$ of patients diagnosed in 1973-1979 receiving radiotherapy compared with $16 \%$ in $2000-2008$. The use of radiotherapy was more common in SCC (53.0\% vs $17.5 \%$ in non-SCC) and increased over the study period in SCC (48.9\% vs $53.4 \%$ in 1973-1979 and 2000-2008, respectively). Use of radiotherapy was associated with a longer survival in all epithelial histologies, except in neuroendocrine carcinomas ( $\mathrm{SCC} \mathrm{HR}=0.50, \mathrm{CI}=0.48-0.53$, $P<0.001 ;$ adeno $\mathrm{HR}=0.73, \quad \mathrm{CI}=0.71-0.75, \quad P<0.001 ; \quad \mathrm{NOS}$ $\mathrm{HR}=0.60, \quad \mathrm{CI}=0.59-0.62, \quad P<0.001 ; \quad$ and neuroendocrine $\mathrm{HR}=1.05, \mathrm{CI}=0.94-1.17, P=0.38)$. Radiotherapy use was also more common in males (23.3 vs $15.6 \%$ ), whites (19.8 vs $17.1 \%$ in blacks), patients younger than $65(29.6 \%$ vs $14.3 \%)$ and residents of more affluent counties (19.1 vs 17.0\%). The differences in radiotherapy use were more pronounced in patients with SCCs, which were the group most likely to benefit from radiotherapy 


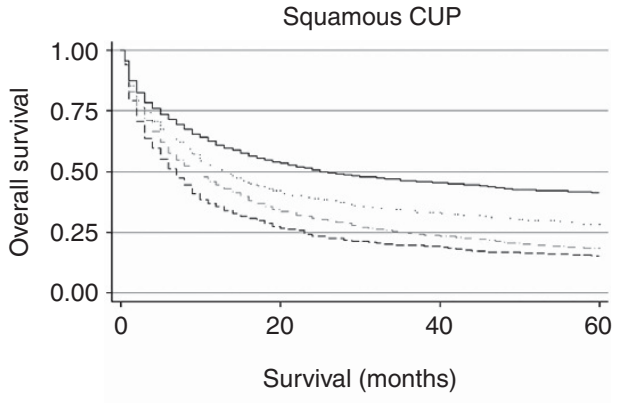

\begin{tabular}{|rr|}
\hline$-1980-1989$ \\
\hline - 1973-1979 & 1990-1999 2000-2008 \\
\hline
\end{tabular}
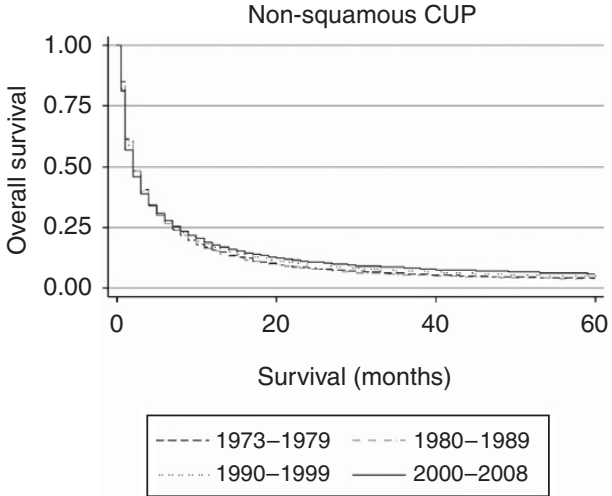

Figure 4. The Kaplan-Meier overall survival curves by histology, divided into SCC and non-SCC.

(57.6\% vs $43.5 \%, 62.1 \%$ vs $44.3 \%, 54.6 \%$ vs $46.6 \%$ and $57.6 \%$ vs $50.5 \%$, by gender, age, race and affluence, respectively).

\section{DISCUSSION}

To our knowledge, this is the largest study examining trends and socioeconomic disparities in CUP. Our study shows that both the incidence and the proportion of CUP diagnoses have decreased over time, with the latter decreasing to a greater extent with $<2 \%$ of cancers currently being diagnosed as CUP. In addition, there are significant socioeconomic disparities in the diagnosis, treatment and survival of patients with CUP.

The trends in CUP incidence in the United States are similar to previously reported non-US studies but the peak incidence in the US population occurred more than a decade before similar peaks in Australia and Sweden (Luke et al, 2008; Shu et al, 2012). This may reflect differences in the widespread use of newer diagnostic techniques, or alternatively may suggest differences in biology and risk factors for cancer (such as rates of smoking) between the populations. This low incidence is comparable to other recently published papers (Randén et al, 2009; Brustugun and Helland, 2013).

In contrast to the initial increase in CUP incidence, our results show a steady decrease in the proportion of CUP from the beginning of the study period. One possible explanation for this greater reduction in proportion compared with the incidence is an improvement in diagnostic techniques. This is supported by reports of greater rates of ascertaining a primary site with the use of more sophisticated immunohistochemistry (Oien, 2009), better imaging, such as combined computer tomography and positron emission tomography scans (Sève et al, 2007; Kwee and Kwee, 2009) and modern gene expression profiling (Hainsworth et al, 2013).

Furthermore, the fact that there is a greater proportion of CUP diagnoses in certain groups such as older patients, blacks, less affluent and those with lower education may be reflective of limited access to modern diagnostic tests. This is in keeping with Australian data showing that the rate of diagnosis of CUP is highest amongst indigenous Australians (Luke et al, 2008). The fact that blacks in affluent areas have rates similar to whites suggests that the biological differences between races per se do not fully explain these disparities. Moreover, the more affluent and educated are more likely to have a diagnostic confirmation of cancer, substantiating that socioeconomic factors do impact on the diagnostic workup. This is in keeping with multiple studies highlighting differences in cancer staging procedures between different racial/socioeconomic groups (Merrill et al, 2000; Gould et al, 2011) and among the elderly (Wedding and Lichtman, 2013).
It is not likely that improved diagnostics will entirely eliminate CUP as an entity, as there remain a proportion of cancer patients where a primary site is not found even after autopsy (Al-Brahim et al, 2005). However, our results do suggest that some of the discrepancies between the rates of CUP in different socioeconomic groups can be explained by differential access to diagnostic investigations. Such disparities are well recognised (Rachet et al, 2008) and has prompted the American Society of Clinical Oncology to release a set of recommendations to decrease disparities (Moy et al, 2011). Unless these inequalities are resolved, there is a risk for even greater disparities with the advent of new and costly technologies, such as gene expression profiling, which may influence treatment recommendations and potentially amplify survival differences (Hainsworth et al, 2013).

One of the striking findings is that the overall prognosis for patients diagnosed with CUP remains poor, with an overall median survival of 3 months. It is noteworthy that only SCCs recorded an improvement in survival. This finding is in contrast to an Australian study where all histological types recorded an improvement over time (Luke et al, 2008) and to many other solid tumours, where improvements in survival have been recorded ((Edwards et al, 2010; Coleman et al, 2011). Likewise, recent reviews of CUP report the median survival as ranging from 8 to 12 months (Greco et al, 2012; Lee et al, 2013), which may be an overestimate of the true value in the general community. One of the strengths of using population-based data is the inclusion of those patients with the poorest prognosis who may not be referred to an academic centre or enrolled onto a clinical trial.

The lack of improvement in the survival over time in patients with non-squamous CUP may actually reflect a type of selection bias. As the proportion of cancers diagnosed as CUP has decreased over time, those remaining without a site of origin may reflect tumours with the poorest prognosis. These patients may then be denied tumour-specific chemotherapy or molecularly targeted therapy, which may further explain the poor outcomes in this group.

This is in contrast to the improvement in the survival seen in SCC CUP. This better survival for SCC CUP compared with nonsquamous CUP is similar to a recent report from a Canadian-based population registry (Kim et al, 2013). It is difficult to infer causality for the improved survival seen in the SCC subtype, but more aggressive treatment associated with nodal SCC may have a role. It has been demonstrated that a greater percentage of patients with SCC have nodal-only disease (56\% vs $32 \%$ for adenocarcinoma; Hemminki et al, 2012) and nodal CUP is associated with a better survival (Shu et al, 2012). As the majority of SCC nodal CUP are diagnosed in the head and neck and inguinal regions, our 5 year survival of $41.1 \%$ in the entire SCC group may be comparable to the over 50\% 10-year survival of SCC of the head and neck and inguinal region (Hemminki et al, 2012). This would be consistent with data that SCC CUP have similar survival outcomes to SCC 


\begin{tabular}{|c|c|c|c|c|}
\hline & \multicolumn{2}{|c|}{ Univariate } & \multicolumn{2}{|c|}{ Multivariate analysis ${ }^{a}$} \\
\hline & $\mathrm{HR}(\mathrm{Cl})$ & $\boldsymbol{P}$-value & $\mathrm{HR}(\mathrm{Cl})$ & $P$-value \\
\hline \multicolumn{5}{|l|}{ Race } \\
\hline $\begin{array}{l}\text { White } \\
\text { Black } \\
\text { Other }\end{array}$ & $\begin{array}{c}1 \\
1.12(1.09-1.14) \\
0.99(0.96-1.02)\end{array}$ & $\begin{array}{c}<0.001 \\
0.55\end{array}$ & $\begin{array}{c}1 \\
1.11(1.08-1.14) \\
0.95(0.91-0.98)\end{array}$ & $\begin{array}{r}<0.001 \\
0.005\end{array}$ \\
\hline \multicolumn{5}{|l|}{ Age } \\
\hline $\begin{array}{l}<65 \\
\geqslant 65\end{array}$ & $\begin{array}{c}1 \\
1.61(1.58-1.63)\end{array}$ & $<0.001$ & $\begin{array}{c}1 \\
1.43(1.40-1.46)\end{array}$ & $<0.001$ \\
\hline \multicolumn{5}{|l|}{ Decade } \\
\hline $\begin{array}{l}1973-79 \\
1980-89 \\
1990-99 \\
2000-08\end{array}$ & $\begin{array}{c}1 \\
1(0.97-1.02) \\
0.94(0.92-0.96) \\
0.87(0.85-0.89)\end{array}$ & $\begin{array}{c}0.69 \\
<0.001 \\
<0.001\end{array}$ & $\begin{array}{c}1 \\
0.98(0.96-1.0)\end{array}$ & 0.03 \\
\hline \multicolumn{5}{|l|}{ Grade $^{b}$} \\
\hline $\begin{array}{l}1 \\
2 \\
3 \\
4\end{array}$ & $\begin{array}{c}1 \\
1.29(1.18-1.40) \\
1.38(1.28-1.49) \\
1.46(1.34-1.58)\end{array}$ & $\begin{array}{l}<0.001 \\
<0.001 \\
<0.001\end{array}$ & & \\
\hline \multicolumn{5}{|l|}{ Sex } \\
\hline $\begin{array}{l}\text { Male } \\
\text { Female }\end{array}$ & $\begin{array}{c}1 \\
1.05(1.04-1.07)\end{array}$ & $<0.001$ & $\begin{array}{c}1 \\
0.86(0.84-0.88)\end{array}$ & $<0.001$ \\
\hline \multicolumn{5}{|l|}{ Radiotherapy } \\
\hline $\begin{array}{l}\text { None } \\
\text { RT } \\
\text { Refused }\end{array}$ & $\begin{array}{c}1 \\
0.56(0.55-0.57) \\
1.04(0.97-1.1)\end{array}$ & $\begin{array}{c}<0.001 \\
0.28\end{array}$ & \begin{tabular}{c|}
1 \\
$0.68(0.66-0.69)$ \\
$0.96(0.89-1.04)$
\end{tabular} & $\begin{array}{c}<0.001 \\
0.28\end{array}$ \\
\hline \multicolumn{5}{|l|}{ Histology } \\
\hline $\begin{array}{l}\text { Adeno } \\
\text { NOS } \\
\text { SqCC } \\
\text { Neuroendocrine }\end{array}$ & $\begin{array}{c}1 \\
1.06(1.04-1.08) \\
0.39(0.38-0.40) \\
0.49(0.47-0.52)\end{array}$ & $\begin{array}{l}<0.001 \\
<0.001 \\
<0.001\end{array}$ & \begin{tabular}{c|}
1 \\
$0.94(0.92-0.97)$ \\
$0.40(0.38-0.41)$ \\
$0.49(0.47-0.51)$
\end{tabular} & $\begin{array}{l}<0.001 \\
<0.001 \\
<0.001\end{array}$ \\
\hline \multicolumn{5}{|c|}{ Pathological confirmation } \\
\hline $\begin{array}{l}\text { Yes } \\
\text { No }\end{array}$ & $\begin{array}{c}1 \\
1.72(1.69-1.76)\end{array}$ & $<0.001$ & $\begin{array}{c}1 \\
1.39(1.35-1.44)\end{array}$ & $<0.001$ \\
\hline \multicolumn{5}{|l|}{ Marital status } \\
\hline $\begin{array}{l}\text { Married } \\
\text { Previously } \\
\text { married } \\
\text { Single }\end{array}$ & $\begin{array}{c}1 \\
1.29(1.27-1.31) \\
1.11(1.08-1.13)\end{array}$ & $\begin{array}{l}<0.001 \\
<0.001\end{array}$ & $\begin{array}{c}1 \\
1.20(1.17-1.23) \\
1.17(1.14-1.21)\end{array}$ & $\begin{array}{l}<0.001 \\
<0.001\end{array}$ \\
\hline \multicolumn{5}{|c|}{ Education level ${ }^{c}$} \\
\hline $\begin{array}{l}\text { Lowest } \\
\text { education } \\
\text { Second quartile } \\
\text { Third quartile } \\
\text { Highest } \\
\text { education }\end{array}$ & $\begin{array}{l}0.97(0.94-1.0) \\
0.97(0.95-1.0) \\
0.94(0.92-0.96)\end{array}$ & $\begin{array}{c}0.02 \\
0.02 \\
<0.001\end{array}$ & \begin{tabular}{l|c|}
\multicolumn{1}{c|}{1} \\
$0.96(0.94-0.99)$ \\
$0.97(0.95-1.0)$ \\
$0.95(0.93-0.98)$
\end{tabular} & $\begin{array}{l}0.01 \\
0.04 \\
0.001\end{array}$ \\
\hline \multicolumn{5}{|l|}{ Poverty ${ }^{c}$} \\
\hline $\begin{array}{l}\text { Affluent } \\
\text { Middle } \\
\text { Poor }\end{array}$ & $\begin{array}{c}1 \\
1.04(1.02-1.06) \\
1.02(0.99-1.06)\end{array}$ & $\begin{array}{c}<0.001 \\
0.26\end{array}$ & $\begin{array}{c}1 \\
1.02(1.00-1.04) \\
1.03(0.98-1.07)\end{array}$ & $\begin{array}{l}0.05 \\
0.25\end{array}$ \\
\hline $\begin{array}{l}\text { Abbreviations: } \mathrm{Cl}=\mathrm{c} \\
\mathrm{RT}=\text { radiotherapy; } \mathrm{Sc} \\
{ }^{\mathrm{a}} \text { On the basis of } 512 \\
\mathrm{~b}_{\text {Grade was exclude }} \\
\mathrm{c}_{\text {Education level and }}\end{array}$ & $\begin{array}{l}\text { nfidence interval; } \mathrm{HR}= \\
\mathrm{CC}=\text { squamous. } \\
4 \text { out of } 56661 \text { patien } \\
\text { on multivariate analys } \\
\text { poverty are for patient }\end{array}$ & $\begin{array}{l}=\text { hazard ratio } \\
\text { s diagnosed } \\
\text { s as only } 978 \\
\text { diagnosed }\end{array}$ & $\begin{array}{l}\text {; } N O S=\text { not otherwis } \\
83 \text { patients had data } \\
8 \text { ince } 1990 \text {. } \\
\text { sith ald }\end{array}$ & $\begin{array}{l}\text { e specified; } \\
\text { ata. } \\
\text { for grade. }\end{array}$ \\
\hline
\end{tabular}

with known primaries (Kim et al, 2013). It is plausible that patients with nodal-only SCC receive more aggressive therapy such as surgery and/or radiotherapy, with the latter being supported by our data. Moreover, the more substantial improvement in SCC in whites compared with blacks parallels an increase in the use of RT in whites, suggesting disparities in treatment. Unfortunately, the SEER data does not accurately classify isolated, anatomically specific nodal carcinoma of unknown primary, as highlighted by only 94 patients being recorded as diagnosed with non-heamatological malignancies of specific lymph nodes, such as the head and neck, axilla and inguinal regions. This is in contrast to other databases (Hemminki et al, 2012) and should be reviewed by SEER.

As with many population-based analyses, this study has a number of limitations. By its very nature, it is a retrospective study of available data, and given the size of the database there are limits to the clinical relevance of significant $P$-values. In addition, there is a lack of information about confounders such as patients' co-morbidities, the stage of the cancer, performance status and the use of systemic therapies. Notably, SEER has classified over $20 \%$ of patients as CUP without a histological confirmation. This is consistent with other cancer registry data (Tracey et al, 2008) but is in contrast to current definitions of CUP, which require a histological confirmation of metastatic cancer (Pavlidis and Pentheroudakis, 2010). It is of significant concern that large numbers of patients, particularly from disadvantaged backgrounds have been given a label of CUP without actually having a biopsy that may have revealed a much more treatable cancer or other condition.

From SEER we cannot evaluate the diagnostic workup implemented, but given that over $20 \%$ did not have a histological diagnosis, one can postulate that many of these patients had only limited evaluation. One could propose the SEER registry should reclassify 'unknown primary site' into groups, such as 'CUP', for those who have a histological confirmation and a defined minimum diagnostic workup, and 'other' to include other cases, either not histologically confirmed or those with primary site unspecified or not investigated.

In spite of these limitations, this study provides further insight into the heterogeneity of outcomes for patients with CUP and the nature of change that has occurred over time. The proportion of cancers diagnosed as CUP has decreased steadily over time, probably reflecting improved diagnostic investigations. The prognosis of CUP patients is poor but highly dependent on the histological type. The disparities demonstrated in this study highlight the need for policy interventions to ensure that the most vulnerable and disadvantaged patients with CUP have access to all available advances in diagnostic and therapeutic modalities.

\section{REFERENCES}

Abbruzzese JL, Abbruzzese MC, Lenzi R, Hess KR, Raber MN (1995) Analysis of a diagnostic strategy for patients with suspected tumors of unknown origin. J Clin Oncol 13(8): 2094-2103.

Al-Brahim N, Ross C, Carter B, Chorneyko K (2005) The value of postmortem examination in cases of metastasis of unknown origin-20-year retrospective data from a tertiary care center. Ann Diagn Pathol 9(2): 77-80.

Boyland L, Davis C (2008) Patients' experiences of carcinoma of unknown primary site: dealing with uncertainty. Palliat Med 22(2): 177-183.

Bridgewater J, Van Laar R, Floore A, Veer LVT (2008) Gene expression profiling may improve diagnosis in patients with carcinoma of unknown primary. Br J Cancer 98(8): 1425-1430.

Brustugun OT, Helland Å (2013) Rapid reduction in the incidence of cancer of unknown primary. A population-based study. Acta Oncol; e-pub ahead of print 4 April 2013.

Coleman MP, Forman D, Bryant H, Butler J, Rachet B, Maringe C, Nur U, Tracey E, Coory M, Hatcher J, McGahan CE, Turner D, Marrett L, 
Gjerstorff ML, Johannesen TB, Adolfsson J, Lambe M, Lawrence G, Meechan D, Morris EJ, Middleton R, Steward J, Richards MA (2011) Cancer survival in Australia, Canada, Denmark, Norway, Sweden, and the UK, 1995-2007 (the International Cancer Benchmarking Partnership): an analysis of population-based cancer registry data. Lancet 377(9760): 127-138.

Edwards BK, Ward E, Kohler BA, Eheman C, Zauber AG, Anderson RN, Jemal A, Schymura MJ, Lansdorp-Vogelaar I, Seeff LC, van Ballegooijen M, Goede SL, Ries LA (2010) Annual report to the nation on the status of cancer, 1975-2006, featuring colorectal cancer trends and impact of interventions (risk factors, screening, and treatment) to reduce future rates. Cancer 116(3): 544-573.

Fong T, Govindan R, Morgensztern D (2008) Cancer of unknown primary. J Clin Oncol 2008 ASCO Ann Meet Proc 26(15S): 22159.

Gould MK, Schultz EM, Wagner TH, Xu X, Ghaus SJ, Wallace RB, Provenzale $\mathrm{D}, \mathrm{Au}$ DH (2011) Disparities in lung cancer staging with positron emission tomography in the Cancer Care Outcomes Research and Surveillance (CanCORS) study. J Thorac Oncol 6(5): 875-883.

Greco FA, Oien K, Erlander M, Osborne R, Varadhachary G, Bridgewater J, Cohen D, Wasan H (2012) Cancer of unknown primary: progress in the search for improved and rapid diagnosis leading toward superior patient outcomes. Ann Oncol 23(2): 298-304.

Hainsworth JD, Rubin MS, Spigel DR, Boccia RV, Raby S, Quinn R, Greco FA (2013) Molecular gene expression profiling to predict the tissue of origin and direct site-specific therapy in patients with carcinoma of unknown primary site: a prospective trial of the sarah cannon research institute. J Clin Oncol 31(2): 217-223.

Hemminki K, Bevier M, Hemminki A, Sundquist J (2012) Survival in cancer of unknown primary site: population-based analysis by site and histology Ann Oncol 23(7): 1854-1863.

Kim C, Hannouf M, Brackstone M, Winquist E, Zaric G (2013) Identification of the occult tumor in cancer of unknown primary (CUP): a priority based on histology. J Clin Oncol 31(suppl; abstr 1605).

Koepsell T, Weiss N (2003) Epidemiologic Methods: Studying The Occurence Of Illness. Oxford University Press: New York, NY, USA.

Kwee TC, Kwee RM (2009) Combined FDG-PET/CT for the detection of unknown primary tumors: systematic review and meta-analysis. Eur Radiol 19(3): 731-744.

Lee J, Hahn S, Kim DW, Kim J, Kang SN, Rha SY, Lee KB, Kang JH, Park BJ (2013) Evaluation of survival benefits by platinums and taxanes for an unfavourable subset of carcinoma of unknown primary: a systematic review and meta-analysis. Br J Cancer 108(1): 39-48.

Luke C, Koczwara B, Karapetis C, Pittman K, Price T, Kotasek D, Beckmann K, Brown MP, Roder D (2008) Exploring the epidemiological characteristics of cancers of unknown primary site in an Australian population: implications for research and clinical care. Aust N Z J Public Health 32(4): 383-389.

Merrill RM, Merrill AV, Mayer LS (2000) Factors associated with no surgery or radiation therapy for invasive cervical cancer in Black and White women. Ethn Dis 10(2): 248-256.
Morris GJ, Greco FA, Hainsworth JD, Engstrom PF, Scialla S, Jordan 3rd WE, Thomas LC (2010) Cancer of unknown primary site. Semin Oncol 37(2): 71-79.

Moy B, Polite BN, Halpern MT, Stranne SK, Winer EP, Wollins DS, Newman LA (2011) American Society of Clinical Oncology policy statement: opportunities in the patient protection and affordable care act to reduce cancer care disparities. J Clin Oncol 29(28): 3816-3824.

Muir C (1995) Cancer of unknown primary site. Cancer 75(1 Suppl): 353-356.

Muir C (2006) Cancer of unknown primary site. Cancer 75(S1): 353-356.

Oien KA (2009) Pathologic evaluation of unknown primary cancer. Semin Oncol 36(1): 8-37.

Pavlidis N, Pentheroudakis G (2010) Cancer of unknown primary site: 20 questions to be answered. Ann Oncol 21(Suppl 7): vii303-vii307.

Pavlidis N, Pentheroudakis G (2012) Cancer of unknown primary site. Lancet 379(9824): 1428-1435.

Rachet B, Woods L, Mitry E, Riga M, Cooper N, Quinn M, Steward J, Brenner H, Estève J, Sullivan R (2008) Cancer survival in England and Wales at the end of the 20th century. Br J Cancer 99: S2-S10.

Randén M, Rutqvist L-E, Johansson H (2009) Cancer patients without a known primary: incidence and survival trends in Sweden 1960-2007. Acta Oncol 48(6): 915-920.

Sève P, Billotey C, Broussolle C, Dumontet C, Mackey JR (2007) The role of 2-deoxy-2-[F-18]fluoro-D-glucose positron emission tomography in disseminated carcinoma of unknown primary site. Cancer 109(2): 292-299.

Shu X, Sundquist K, Sundquist J, Hemminki K (2012) Time trends in incidence, causes of death, and survival of cancer of unknown primary in Sweden. Eur J Cancer Prev 21(3): 281-288.

Singh G, Miller B, Hankey B, Edwards B (2003) Area Socioeconomic Variations in U.S. Cancer Incidence, Mortality, Stage, Treatment, and Survival, 1975-1999. National Cancer Institute: Bethesda, MD, USA, NIH Publication No. 03-5417.

Surveillance, Epidemiology, and End Results (SEER) Program Research Data (1973-2009). National Cancer Institute, DCCPS, Surveillance Research Program, Surveillance Systems Branch, released April 2012, based on November 2011 submission, www.seer.cancer.gov.

Tracey E, Glass P, Roder D, Currow D, Jelfs P, Bishop J (2008) Unknown Primary Cancer in New South Wales. Cancer Institute NSW: New South Wales, Sydney, Australia.

Wedding U, Lichtman SM (2013) Treatment decisions and medical treatment of cancer in elderly patients. In Drug Therapy for the Elderly. Springer: Vienna, pp 229-247.

This work is published under the standard license to publish agreement. After 12 months the work will become freely available and the license terms will switch to a Creative Commons AttributionNonCommercial-Share Alike 3.0 Unported License. 